\title{
Investigation on the effect of opening position across an isolated building for wind- driven cross ventilation
}

\author{
L.K. Moey ${ }^{1}$, K.L. Chan², V.C. Tai ${ }^{1}$, T.F. Go ${ }^{3}$ and P.L. Chong ${ }^{4}$ \\ ${ }^{1}$ Centre for Modelling and Simulation, Faculty of Engineering, Built Environment \& Information Technology, SEGi University, Selangor, Malaysia \\ Phone: +60361451777 \\ ${ }^{2}$ Faculty of Engineering, Built Environment \& Information Technology, SEGi University, Selangor, Malaysia \\ ${ }^{3}$ Centre for Advance Materials and Intelligent Manufacturing, Faculty of Engineering, Built Environment \& Information Technology, SEGi University, \\ Selangor, Malaysia \\ ${ }^{4}$ School of Computing, Engineering \& Digital Technologies, Teesside University, Middlesbrough, TS1 3BX, United Kingdom
}

ABSTRACT - This study investigates the effect of opening position on the indoor airflow of a natural ventilated isolated building model. Furthermore, the opening configuration which generate the highest ventilation is to be determined. Seven different opening configurations were considered by varying the opening position on the windward and leeward walls which include three cases of aligned openings and four non-aligned openings. Models with different opening position were simulated using Computational Fluid Dynamics (CFD) with 3D RANS turbulence model Shear Stress Transport (SST) $k-\omega$. Simulation result indicates the indoor air velocity as well as pressure distribution highly depends on both inlet and outlet opening positioning. Different opening configuration influences the recirculation zone generated within the building model. Comparison shows openings located near the roof generate $6.52 \%$ higher ventilation rate compared to openings located near the ground. The study concludes that opening position holds a crucial role in affecting internal airflow pattern, air recirculation and ventilation rate for a natural cross ventilated building.
ARTICLE HISTORY

Received: 07 July 2020

Revised: $28^{\text {th }}$ Nov 2020

Accepted: $03^{\text {rd }}$ Jan 2021

\section{KEYWORDS}

Natural ventilation; opening position; airflow pattern; pressure coefficient; ventilation rate

\section{INTRODUCTION}

In recent years, global warming has worsened. The excess use of mechanical ventilation to maintain thermal comfort has become one of the causes of global warming [1] due to high energy consumption to power the mechanical ventilation systems. Rapid economic and population growth in Southeast Asia countries have significantly increase the demand for electricity. About $154.2 \%$ of primary energy consumption was predicted from 2012 to 2030 in ASEAN contributing to $5.7 \%$ increment of carbon dioxide emission annually [1,2]. An alternative energy supply is therefore required to overcome the high dependency on fossil fuel [3]. According to Agrawal, mechanical ventilation appliances such as fans and air conditioners in HVAC system consume high amount of energy for buildings [4]. Based on the report of World Business Council for Sustainable Development (WBCSD), buildings consume a total of $40 \%$ of the world's energy use. Compare a natural ventilated house to air-conditioned house, the carbon released and the energy consumption is about $67 \%$ higher for air-conditioned house. In view of this, WBSCD has advised the building sector to fuse innovative designs, technological innovation, and public policies to incorporate natural ventilation in order to obtain better energy efficiency [5].

Previous studies on natural cross ventilation were done using experimental studies, empirical studies and numerical studies. Among these methods, wind tunnel experiments and CFD are the most widely used by researchers to study natural cross ventilation [6-8]. Karava [9] performed a study on cross ventilation with operable façade elements. The study was done using both uniform and different wall porosity which ranged from $2.5-20 \%$. The study analyzed a $4-$ storey building using a 1:200 scale-model building which undergoes experiment with a Boundary Layer Wind Tunnel (BLWT). Results of aligned openings showed opening near the roof generates higher velocities which then contributes to higher airflow rate compare to openings located at center and near the ground. This study was then used by Meroney [6] as a validation reference to study natural cross ventilation under different opening configurations using CFD. This study also outlined the effect of different turbulence models on cross ventilation simulation study. The building model used in the study was similar to Karava and Ramponi $[9,10]$. However, the computational domain in the simulation was slightly smaller compared to Ramponi [10]. Results of airflow rates showed similar trend as Karava [9] where higher flow rates were observed for openings near the roof.

Kosutova [7] studied cross ventilation in an isolated building with two batches of simulation cases - building openings equipped with louvers and openings without louvers. The building model was simulated under four different opening configurations using three 3D Reynolds-averaged Navier-Stokes (RANS) turbulence models. The result of dimensionless volume flow rate (DFR) showed opening configuration with openings placed near the roof has higher volume flow rate. A study by Tominaga [8] also showed similar result whereby the effect of opening positions on cross-ventilated isolated building was studied using atmospheric boundary layer wind tunnel analysis. Five opening configurations were studied 
and tracer gas method was used to determine the airflow rate through the building. In terms of the airflow rate, cases with openings near the roof had higher flow rate than cases with openings near the ground.

However, opening configuration mentioned in these studies involved only aligned openings and diagonally placed openings which both having the shortest and longest distance between the two openings respectively. In order to fully understand the effect of opening configurations on the indoor airflow pattern and ventilation rate, more opening configurations should be considered. Therefore, this study includes both aligned and diagonally placed openings, with addition of two non-aligned opening configurations that have medium distance between the two openings. The main objective of this study is to investigates the effect of opening position on the indoor airflow of a natural ventilated isolated building model. Furthermore, the opening configuration which brings about the highest ventilation rate can be determined. Numerical study using CFD was carried out using seven different opening configurations to analyze the internal airflow pattern and ventilation rate. Section 2 presents the methodology which includes computational domain, solver setting, grid sensitivity analysis, and model validation study. Then in Section 3, the result from simulations is analyzed and discussed before presenting the conclusion in Section 4.

\section{METHODOLOGY}

\section{Model Geometry, Computational Domain, and Building Configuration}

Figure 1 shows the dimension of the building model and the symmetry plane, based on the reference from Ramponi [10] which is an isolated building. This building was scaled down from its original dimension of $20 \mathrm{~m} \times 20 \mathrm{~m} \times 16 \mathrm{~m}$ (W $\mathrm{x}$ L $\mathrm{x} \mathrm{H}$ ) to the building model using a scale of 1:200. The building model was equipped with two aligned and opposite opening where the openings have the same dimension of $0.046 \mathrm{~m} \mathrm{x} 0.018 \mathrm{~m}(\mathrm{~W} \times \mathrm{H})$ and were placed at the center of the wall. The whole building model has a thickness of $2 \mathrm{~mm}$ at the ceiling, ground, and four sidewalls.

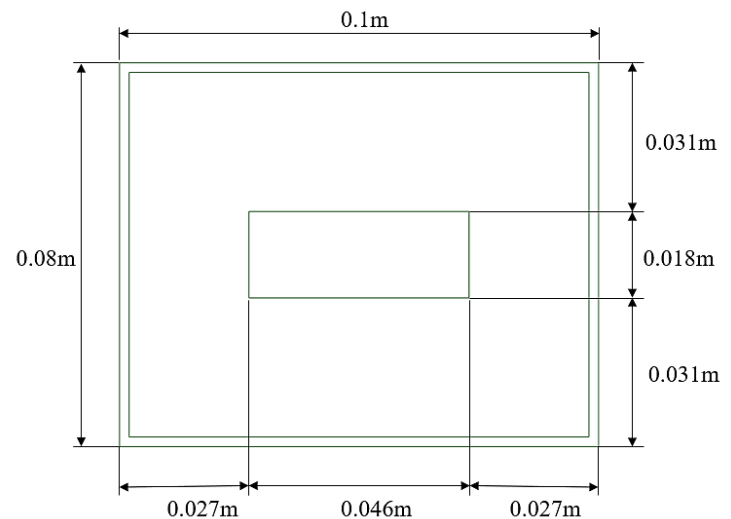

(a)

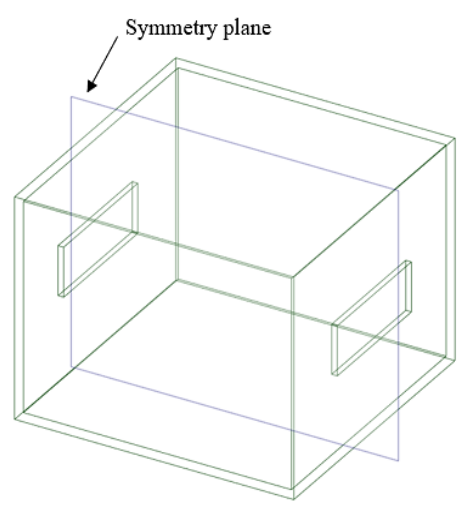

(b)

Figure 1. (a) Model dimensions and (b) Symmetry plane of the model [10]

Computational domain used in this study was based on the reference from Ramponi [10]. As shown in Figure 2, the upstream length from the inlet plane to the model windward wall was set to be $3 \mathrm{H}(0.24 \mathrm{~m})$ which is three times the model height where $\mathrm{H}=0.08 \mathrm{~m}$, to restrict the chances of unintended streamwise gradients to develop. The downstream length from the model leeward wall to the outlet plane was set to be $15 \mathrm{H}(1.2 \mathrm{~m})$ while $5 \mathrm{H}(0.4 \mathrm{~m})$ was set at the lateral side and top of the domain. This results in the computational domain to have a dimension of $0.9 \mathrm{~m} \times 1.54 \mathrm{~m} \times 0.48 \mathrm{~m}(\mathrm{~W} \times \mathrm{L} \times$ $\mathrm{H})$.

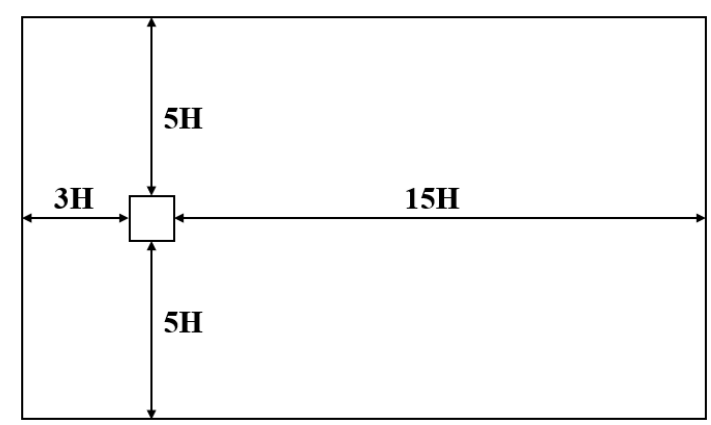

(a)

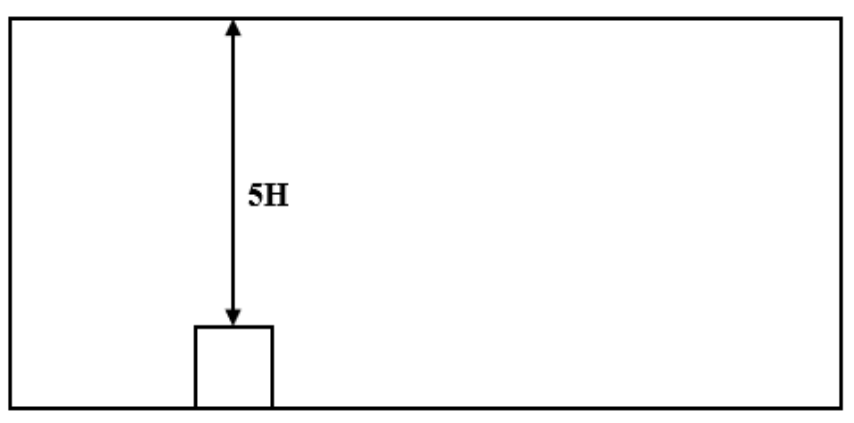

(b)

Figure 2. Dimension of computational domain (a) Top view and (b) Front view 
In this study, different opening positions were considered. A total of seven configurations were applied onto the model for simulation which all have a constant wall porosity of $10 \%$ [9]. Position of openings were varied using heights of 0.015 $\mathrm{m}, 0.04 \mathrm{~m}$, and $0.065 \mathrm{~m}$ on the center axis of the model from windward and leeward walls. Based on Table 1, Cases 1, 2, 3 have aligned openings at both windward and leeward walls while Cases 4, 5, 6, and 7 have non-aligned openings. Meshing process was done using the ANSYS 2019 R3 software. A small domain, known as Body of Influence (BoI), with dimension of $0.625 \mathrm{H}$ was created to encapsulate the building geometry to yield more accurate results obtained with lower calculation time. Meshing process was done by varying the global and local sizing. The total cell count generated for all cases was about 494000 cell count which was determined through grid sensitivity analysis. Polyhexacore mesh was used for more accurate results. [11,12] and uniform prism layer was applied to the building model shown in Figure 3. Using the $y+$ value of 200 , the first cell height was calculated to be $0.01 \mathrm{~mm}$.

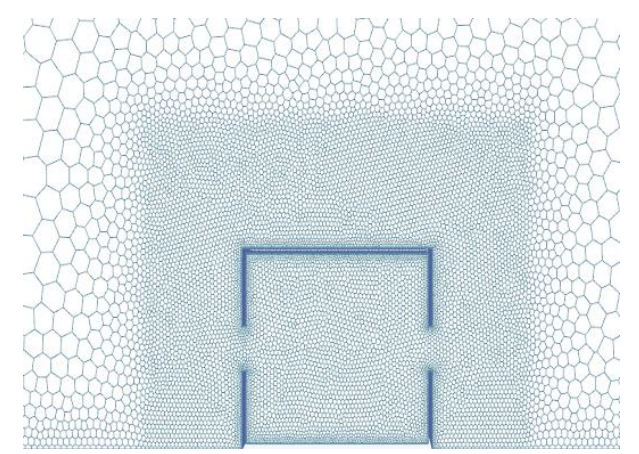

(a)

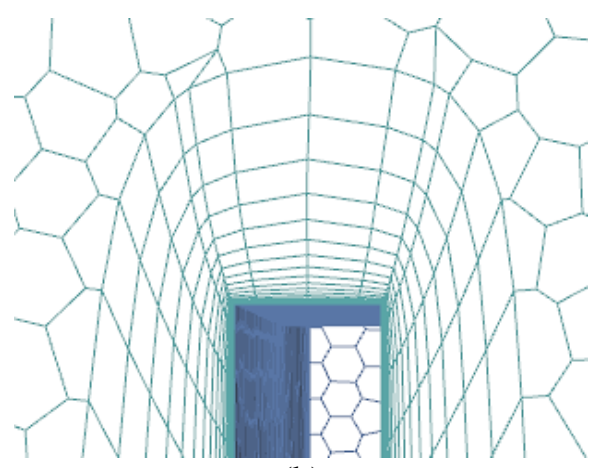

(b)

Figure 3. (a) Final mesh around the model and (b) Inflation layer on the model.

Table 1. Seven opening configurations for simulation

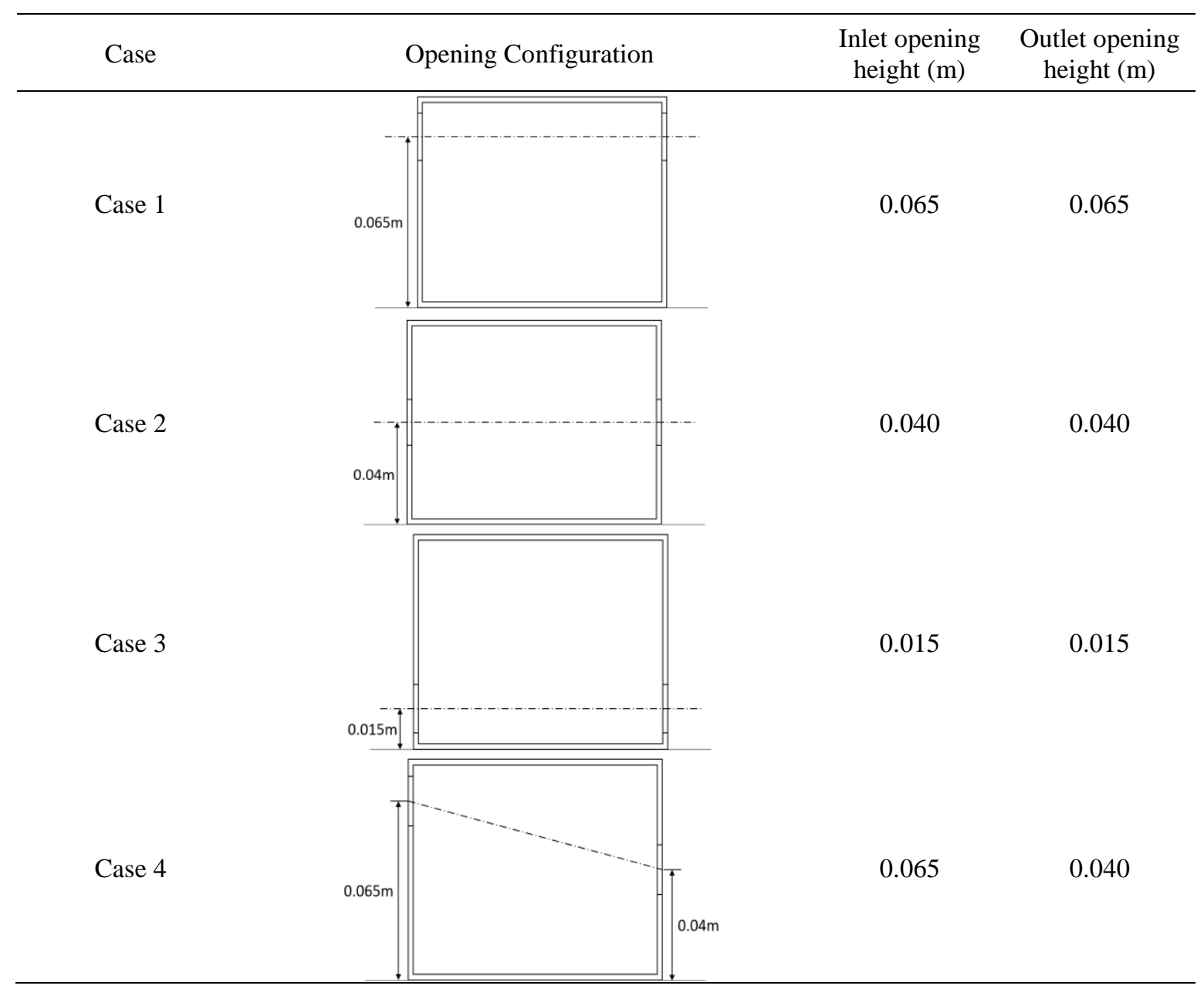


Table 1. Seven opening configurations for simulation (cont.)

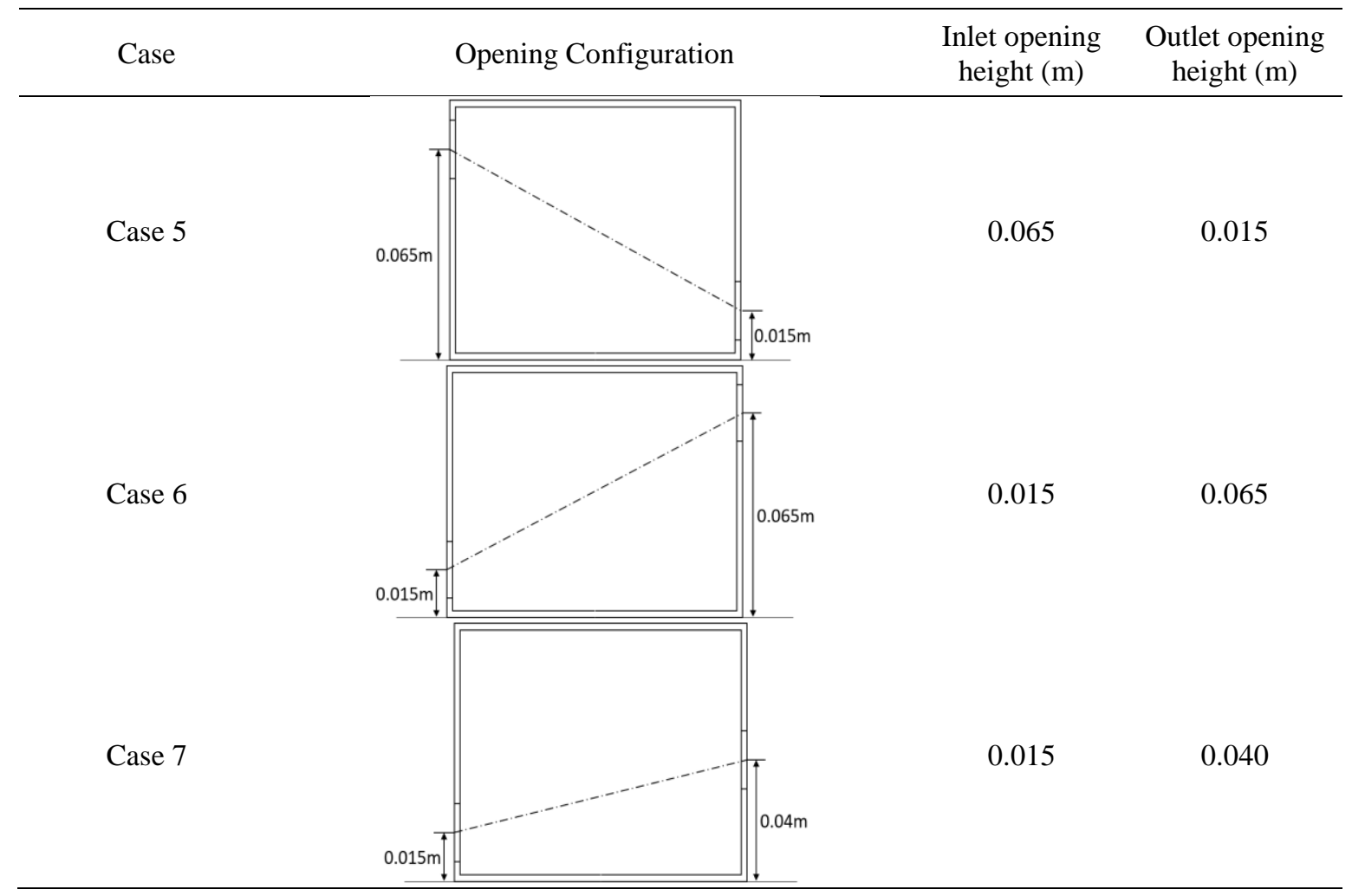

\section{Atmospheric Boundary Layer (ABL) condition}

An ABL file was interpreted to create the velocity profile from the inlet. Eqs. (1) to (5) were applied to determine the key input boundary conditions. By using Eq. (1), ABL friction velocity $U_{A B L}^{*}$ was calculated with reference velocity, $U_{R e f}$ of $6.97 \mathrm{~m} / \mathrm{s}$, reference height, $Z_{R e f}$ of $0.08 \mathrm{~m}$, Von Karman constant, $\kappa$ of 0.4 , and the aerodynamic roughness height $Z_{o}$ of $0.00003 \mathrm{~m} \mathrm{[13].} \mathrm{Then,} \mathrm{the} \mathrm{inlet} \mathrm{velocity} \mathrm{profile} \mathrm{was} \mathrm{determined} \mathrm{using} \mathrm{Eq.} \mathrm{(2)} \mathrm{with} \mathrm{ABL} \mathrm{friction} \mathrm{velocity}$ $U_{A B L}^{*}$. Turbulence kinetic energy, $\mathrm{k}$ was obtained from Eq. (3) with empirical constant $C_{M U}=0.09$ and turbulence dissipation rate was calculated from Eq. (4). The top and side walls were set to have zero specific shear stress while the outlet was set as pressure-outlet. The inlet was set as velocity inlet with values of velocity magnitude, turbulent kinetic energy, and turbulent dissipation rate generated by the ABL file. For the ground sand grain roughness height $k_{s}, 0.0006$ $\mathrm{m}$ was obtained from Eq. (5) by substituting the value of aerodynamic roughness height $Z_{o}=0.00003 \mathrm{~m}$.

$$
\begin{gathered}
U_{A B L}^{*}=\frac{U_{\text {Ref }} \times \kappa}{\log \left(\frac{Z_{\text {Ref }}}{Z_{o}}+1\right)} \\
U=\frac{U_{A B L}^{*}}{\kappa} \log \left(\frac{Z_{\text {Ref }}}{Z_{o}}+1\right) \\
k=\frac{\left(U_{A B L}^{*}\right)^{2}}{\sqrt{C_{M U}}} \\
\varepsilon=\frac{\left(U_{A B L}^{*}\right)^{3}}{k\left(Z_{R e f}+Z_{o}\right)} \\
k_{s}=\frac{9.793 Z_{o}}{C_{s}}=20 Z_{o}
\end{gathered}
$$

\section{Solver Settings}

In this study, CFD simulation was done using ANSYS 2019 R3. Shear Stress Transport (SST) k- $\omega$ turbulence model from the 3D steady-state Reynolds-averaged Navier-Stokes (RANS) equation was applied. SIMPLE scheme was chosen at the Pressure-Velocity Coupling while for the spatial discretization, Green-Gauss Node Based gradient was chosen. 
Second order was chosen for all four pressure, momentum, turbulent kinetic energy, and turbulent dissipation rate [14] to yield more accurate results [10]. Standard Initialization was used and convergence criteria was set to $1 \times 10^{-4}$ for $\mathrm{x}, \mathrm{y}$, z-velocities, $\mathrm{k}$, omega and continuity residuals, while $1 \times 10^{-6}$ for energy.

\section{Grid Sensitivity Analysis}

In this study, grid resolution analysis was done using 3 different grids on the building model which including coarse grid with 281990 cells, medium grid with 412483 cells and fine grid with 493981 cells. Simulation was done using the three grids above and a graph of mean streamline velocity ratio $\left(U / U_{R e f}\right)$ was plotted. Comparison was done with the reference to wind tunnel experiment results conducted by Karava [9]. Figure 4 shows the mean streamwise wind speed $\left(U / U_{R e f}\right)$ along the centerline connecting between the inlet and outlet opening. Grid $\mathrm{A}$, B, and $\mathrm{C}$ represent the coarse, medium, and fine grid, respectively. The analysis shows that grid $\mathrm{C}$ is the closest to the results obtained by wind tunnel experiment by Karava [9]. Table 2 shows the value of percentage difference between grids became smaller as the grid became finer. Hence, Grid C with the cell count of 493981 was chosen to be applied to all models for this study.

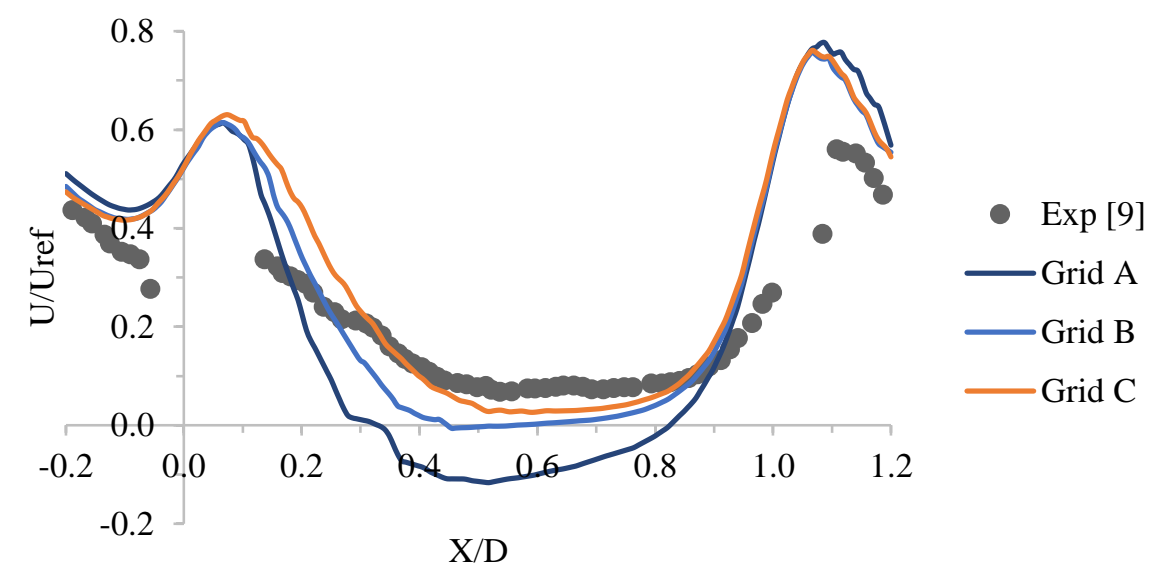

Figure 4. Result of CFD simulation for three grid type and experimental results [9]

Table 2. Percentage difference between different grids

\begin{tabular}{ccc}
\hline Grid type & Number of cells & Percentage Difference $(\%)$ \\
\hline Coarse & 281990 & - \\
Medium & 412483 & 1.48776 \\
Fine & 493981 & 1.18624 \\
\hline
\end{tabular}

\section{Model Validation}

In order to ensure the better accuracy of study, validation was done by comparing CFD simulation results with numerical results from previous study [10]. Case 2 with both openings located at the center of windward and leeward wall was simulated using SST k- $\omega$ turbulence model and the comparison with previous study was done on the velocity vector of the indoor flow. The comparison shows good agreement between two contours where a similar trend of airflow was observed in Figure 5. Hence, this model validation study can be said to be successful and the same solver settings will be applied to all cases in this study. 


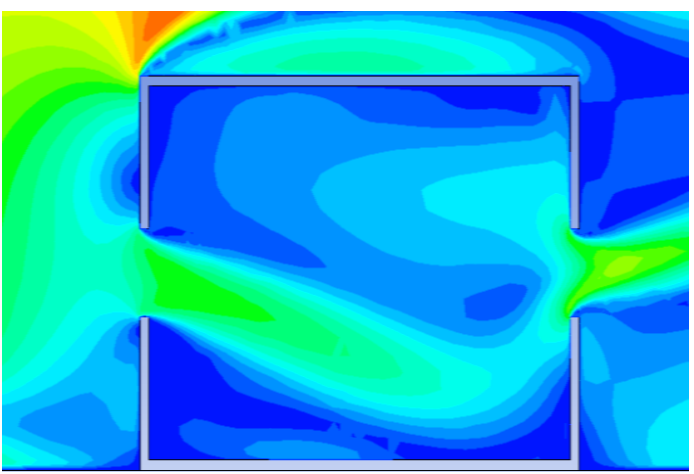

(a)

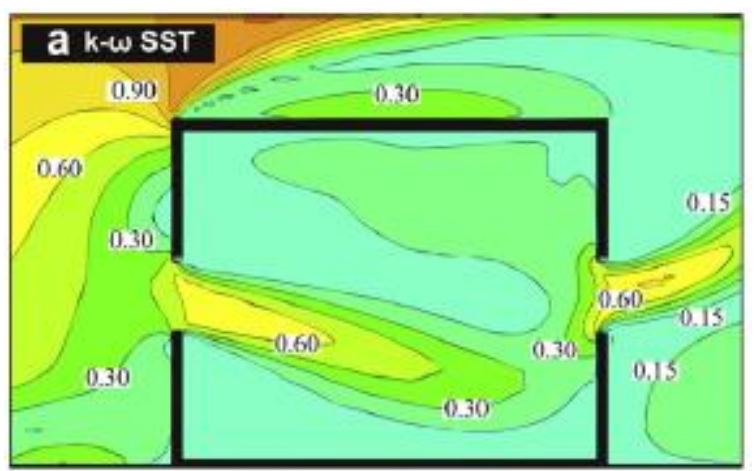

(b)

Figure 5. Velocity contour (a) Case 2 simulation results and (b) Numerical simulation result [10]

\section{RESULTS AND DISCUSSION}

\section{Velocity Vector}

Based on the velocity vector from all seven cases shown in Figure 6, there is a small standing vortex formed at the bottom part outside of the building due to the no-slip condition on the ground. The vortex formation affects the windward flow direction for openings located at $0.015 \mathrm{~m}$ and $0.04 \mathrm{~m}$ above ground which directs the flow downwards as it enters the building. For windward opening located at $0.065 \mathrm{~m}$ above ground, the inlet flow was directed upwards due to the air at the lower half of the building deflects towards the top after hitting the building wall which creates an upward forces at the windward opening.

For Case 2, air enters the building with a downward flow. As airflow through the building, recirculation vortex was formed at both above and below the flow stream. However, the vortex formed above the flow was bigger which leads to the flow exiting the building to flow upwards. For Case 1 and Case 3, a similar but opposite flow pattern was observed. Flow in Case 1 enters the building with an upward trend and travels along the ceiling wall before exits with a downward trend. Flow in Case 3 enters with a downward trend and exits with a upward trend. However, the inlet flow velocity for Case 1 is higher than Case 3 since the incoming flow is not affected by the vortex formation at the bottom part in front of the building.

For Case 4 and Case 5, the pattern of flow leaving at the leeward opening shows an upward trend when the windward opening was placed lower than the leeward opening. On the other hand, an upward trend was observed leaving the leeward opening when the windward opening was placed higher than the leeward openings for Case 6 and Case 7. Both upward and downward flow pattern at the leeward openings can be explained by observing the formation of recirculation vortex zone outside and within the building. The direction and force of the vortex formed affects the airflow pattern when it exits through the leeward openings.

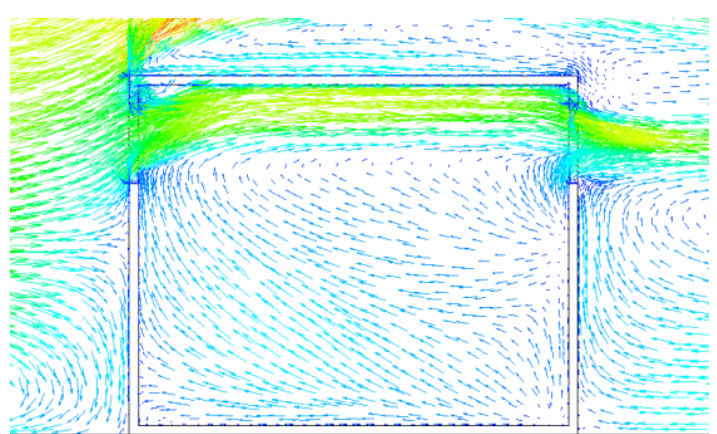

Case 1

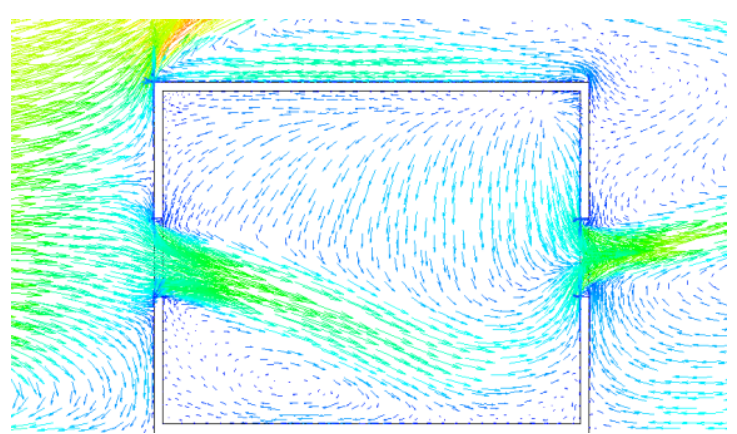

Case 2

Figure 6. Velocity vector for different opening positions 


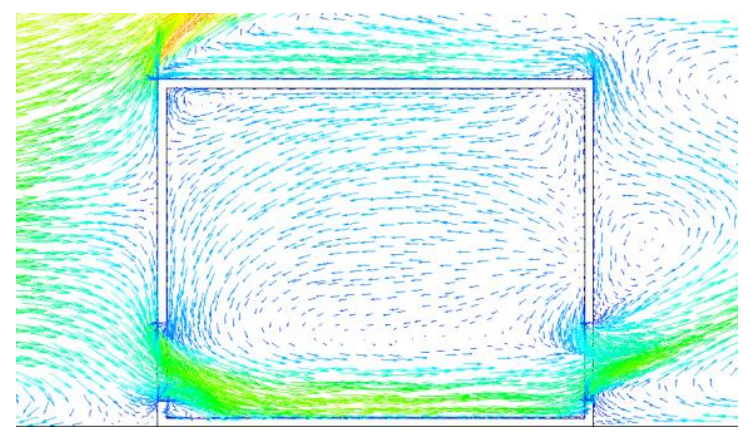

Case 3

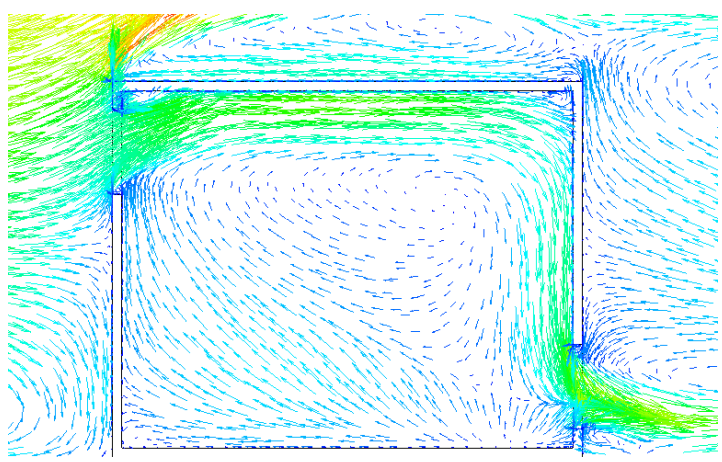

Case 5

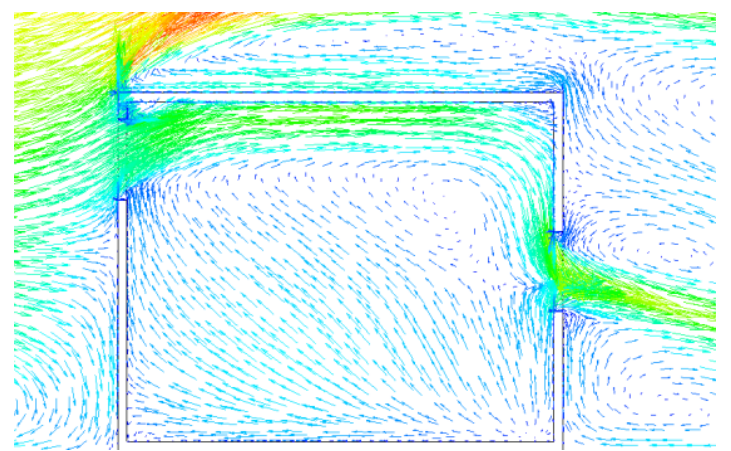

Case 4

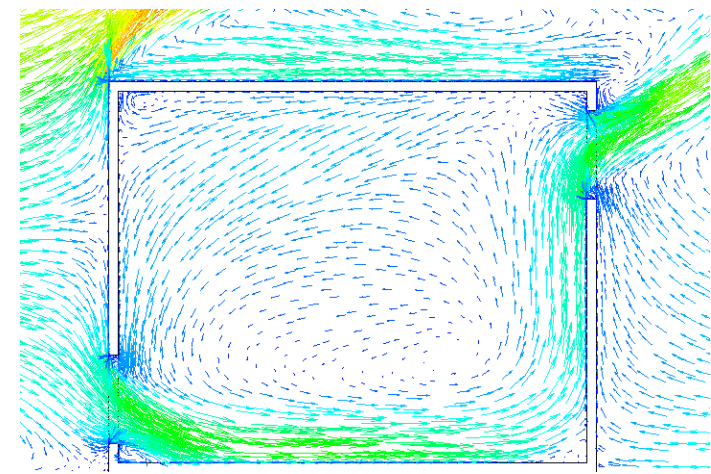

Case 6

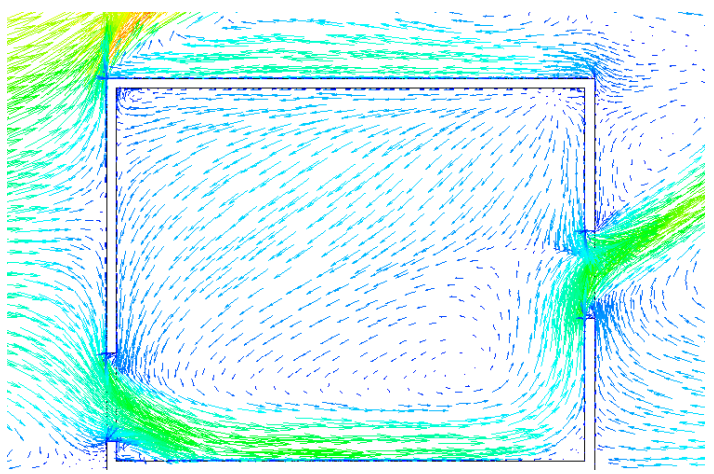

Case 7

Figure 6. Velocity vector for different opening positions (cont.)

\section{Mean Velocity Profile}

Figure 7 shows the wind speed ratio $\left(U / U_{R e f}\right)$ against distance ratio (X/D) for seven cases. The figure was generated using data obtain from the horizontal line placed between two windward and leeward openings. Common trend of airflow can be observed whereby when air with high velocity enters the building through inlet opening, the velocity decreases as it flows toward the middle of building which regains velocity as it approaches the outlet opening.

For the case with aligned openings, the graph of mean streamwise wind speed ratio $\left(U / U_{R e f}\right)$ against distance ratio (X/D) shows that Case 1, with both windward and leeward openings placed on $0.065 \mathrm{~m}$ above ground, has the highest velocity, followed by Case 2 and Case 3. This result shows good agreement with PIV experiments by Karava [9] which indicates aligned openings near the roof have higher velocities compared to aligned openings located at the middle and bottom of the model. Comparison was made at three different location which is the inlet opening $(\mathrm{X} / \mathrm{D}=0.00)$, middle of the building $(X / D=0.50)$, and the outlet opening $(X / D=1.00)$. Case 1 has $13 \%$ and $20 \%$ higher velocity at the inlet opening while having $16.6 \%$ and $28.8 \%$ higher velocity at the outlet opening compared to Case 2 and Case 3 , respectively. For the velocity at the middle of building $(X / D=0.50)$, Case 2 ranked last with the lowest velocity which has $13 \%$ lower velocity compared to Case 3 which ranked second. This can be explained by observing the velocity contour of Case 2 in Figure 8 which indicates the downward trend at $\mathrm{X} / \mathrm{D}=0.50$ location.

For non-aligned opening cases, Case 4 with inlet opening at $0.065 \mathrm{~m}$ height has $12.04 \%$ and $19.69 \%$ higher air velocities at both openings compared to Case 7 with inlet opening at $0.015 \mathrm{~m}$ height. For Case 5 and 6 , result shows inlet opening placed near the roof generates higher air velocity at both openings compared to outlet opening placed near the 
roof. Case 5 with inlet opening at $0.065 \mathrm{~m}$ and outlet opening at $0.015 \mathrm{~m}$ have $8.19 \%$ and $16.62 \%$ higher air velocity compared to Case 6 with opening height at $0.015 \mathrm{~m}$ and $0.065 \mathrm{~m}$ respectively.

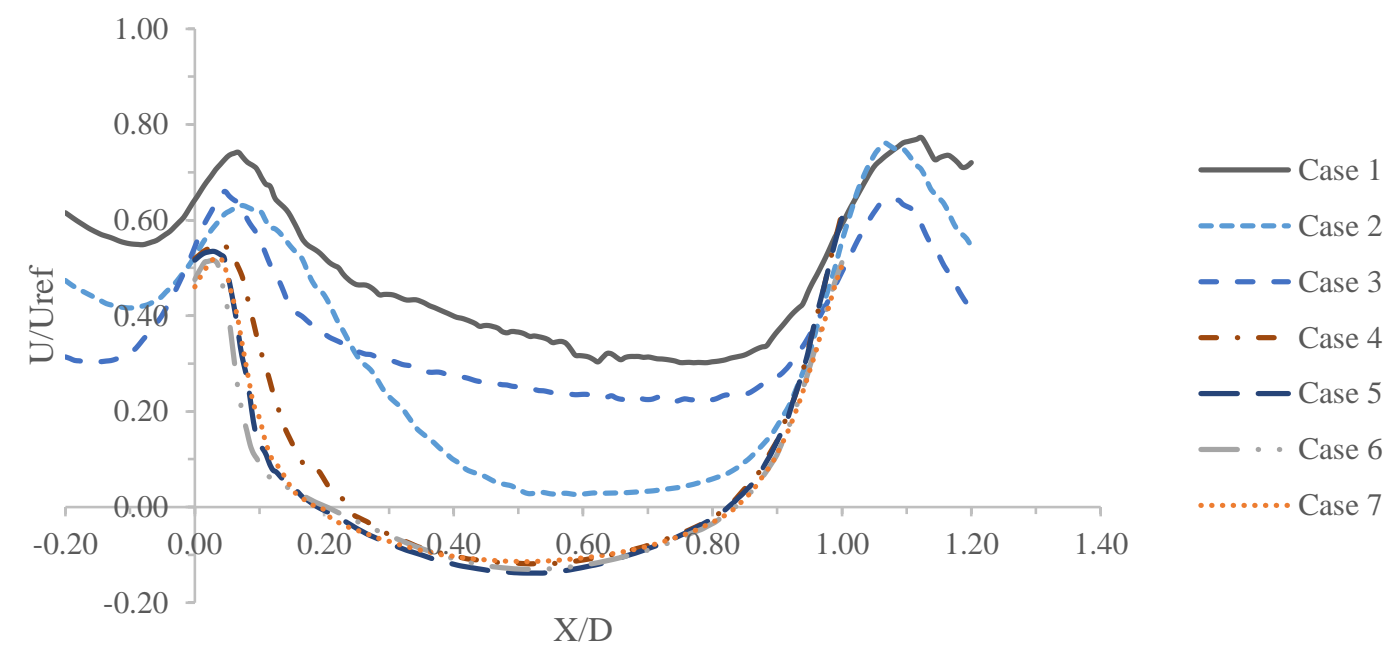

Figure 7. Mean streamwise wind speed ratio $\left(\mathrm{U} / \mathrm{U}_{\mathrm{REF}}\right)$ against distance ratio $(\mathrm{X} / \mathrm{D})$ for seven cases

\section{Velocity and Pressure Contour}

Figure 8 shows the indoor airflow pattern and pressure distribution for all seven cases. The contours show good agreement with the Bernoulli's equation whereby the equation states that fluid velocity is inversely proportional to fluid pressure. As seen in the contour, all seven cases have the highest pressure occurred on the windward wall of $13 \mathrm{~Pa}$ to 22.25 $\mathrm{Pa}$ due to the impact of air colliding to the windward wall while having the lowest pressure value of $0.8 \mathrm{~Pa}$ to 9.1 $\mathrm{Pa}$ at the leeward side of the model. The different pressure values obtained process that changing the position of openings can significantly affect the opening pressure as well as the indoor pressure. This difference in pressure between inlet and outlet opening is the driving force for the wind-induced ventilation where the higher the pressure difference, the higher the air velocity [15]. Comparing the cases with aligned openings, Case 3 has the lowest opening pressure compared to Case 1 and Case 2 for about 31.92\% and 71.15\% at inlet opening. However, Case 3 has the lowest pressure difference between the two openings of $12.2 \mathrm{~Pa}$ followed by Case 2 with $13.65 \mathrm{~Pa}$ and Case 1 with $15.3 \mathrm{~Pa}$. Hence, the velocity at openings at Case 1 will be the highest among these 3 cases. Comparing the non-aligned cases, Case 4 and Case 5 with same inlet opening height at $0.065 \mathrm{~m}$, pressure value of $21.56 \mathrm{~Pa}$ and $22.41 \mathrm{~Pa}$ was obtained which is higher than cases with opening height at $0.015 \mathrm{~m}$, Case 6 and Case 7 with the value of $17.53 \mathrm{~Pa}$ and $21 \mathrm{~Pa}$ respectively.

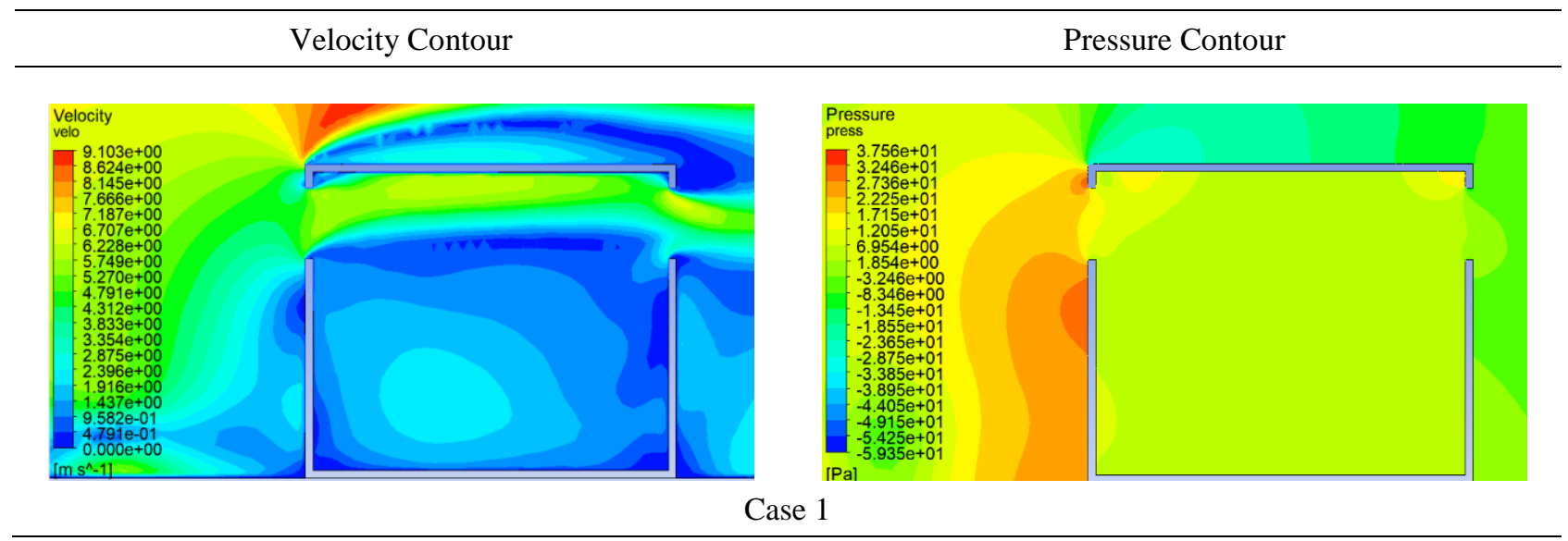

Figure 8. Velocity and pressure contour for different opening position 


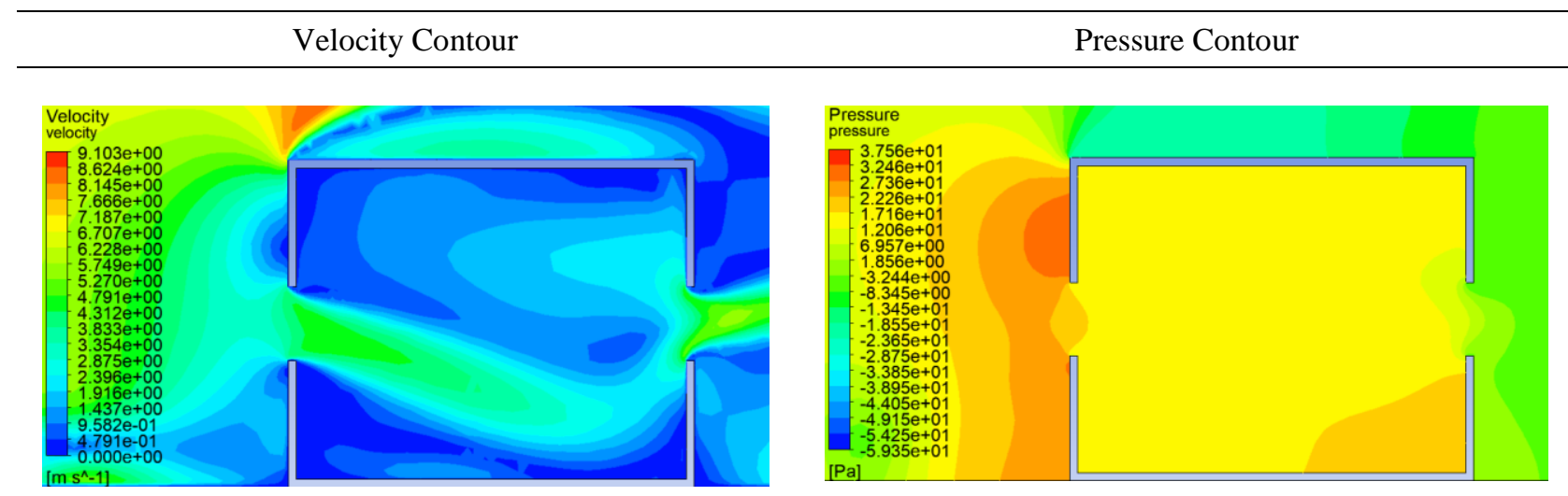

Case 2
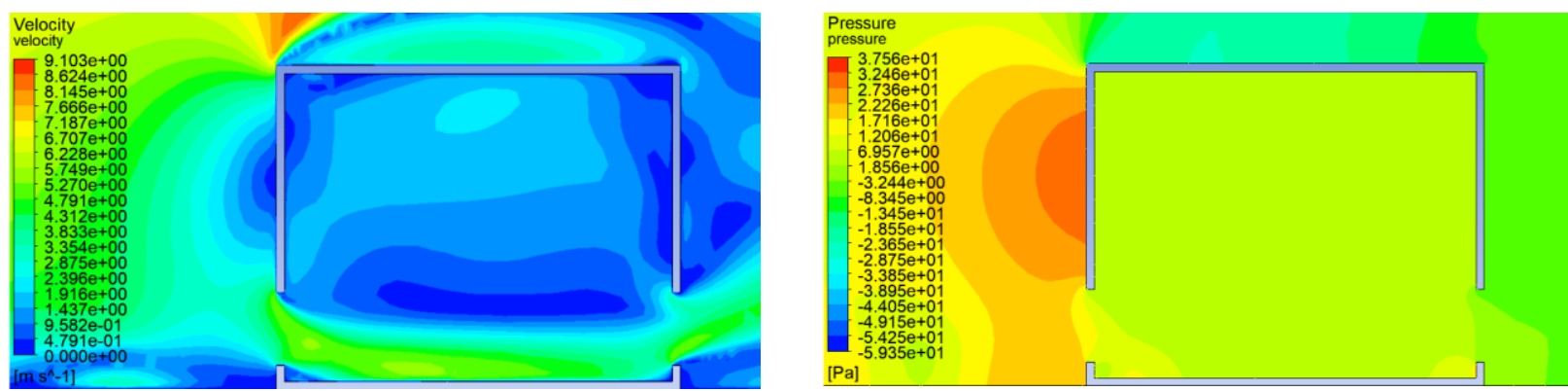

Case 3
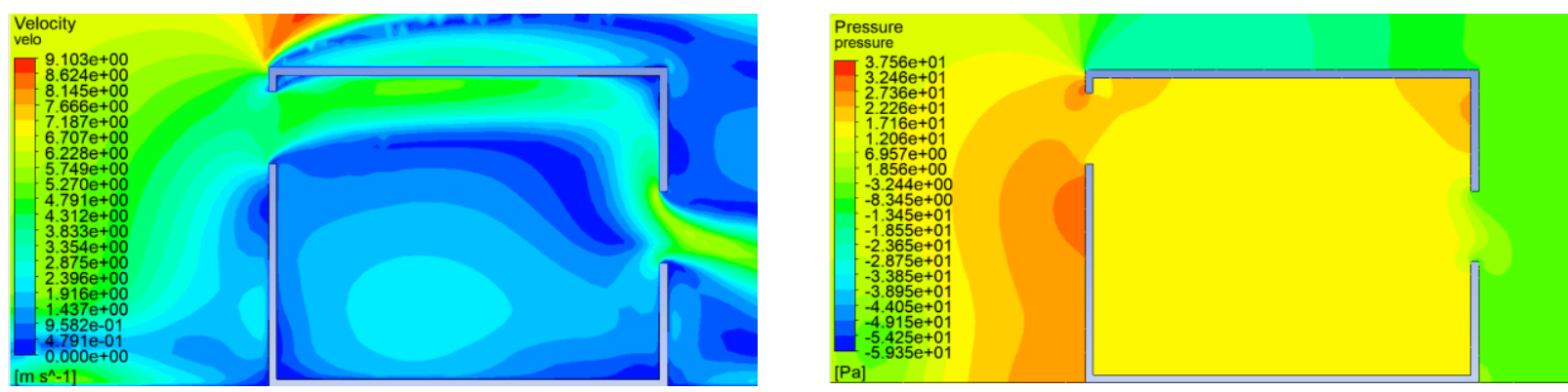

Case 4
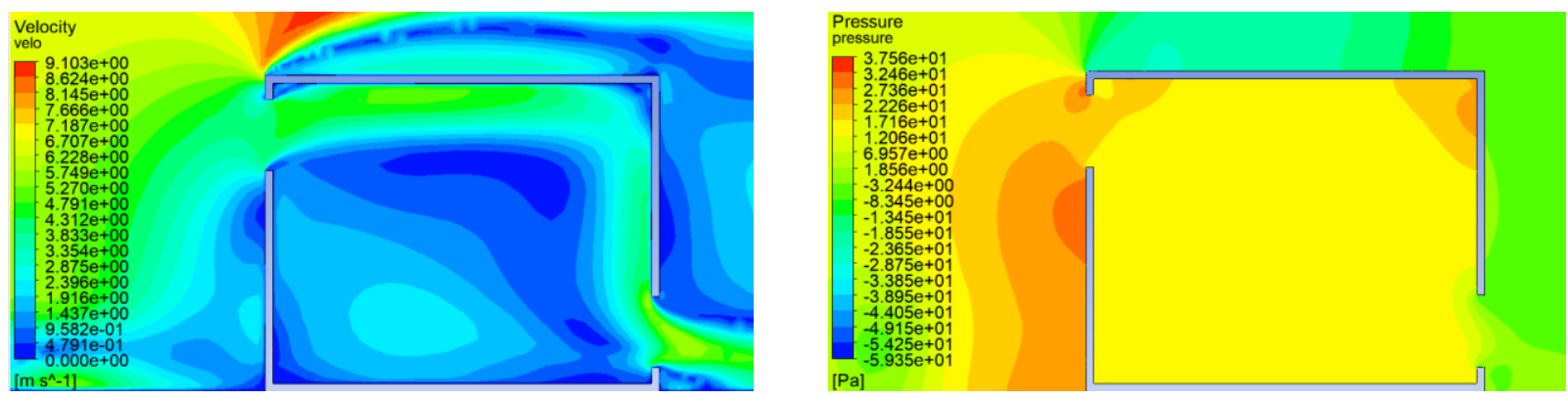

Case 5

Figure 8. Velocity and pressure contour for different opening position (cont.) 


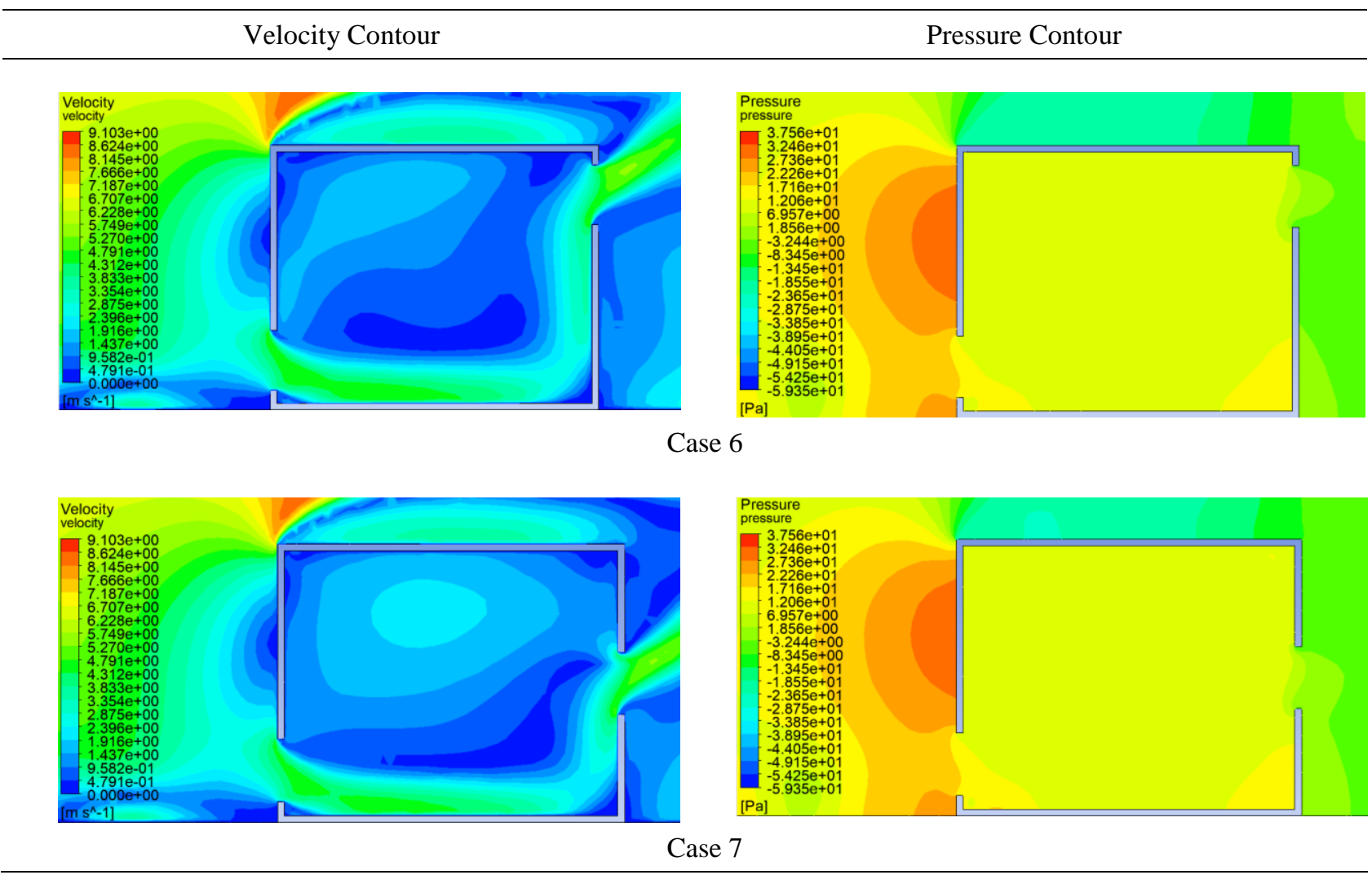

Figure 8. Velocity and pressure contour for different opening position (cont.)

\section{Pressure Coefficient and Ventilation Rate}

Table 3 shows the pressure coefficient obtained from the inlet and outlet openings. Calculations were done to determine the pressure difference between inlet and outlet opening. A common trend was observed which the case with higher air velocity generates high pressure coefficient difference compare to the case with low air velocity. Based on the study by Meroney [6], for low rise building with windows on two walls, the cross ventilation flow rate can be calculated using the equations below:

$$
\begin{gathered}
C p_{\text {internal }}=\left(C p_{\text {in }}+C p_{\text {out }}\right) / 2 \\
Q=C_{\text {Din }} A U_{R E F} \sqrt{C p_{\text {in }}-C p_{\text {internal }}}
\end{gathered}
$$

where,

$$
\begin{array}{ll}
Q & =\text { Cross-ventilation rate }\left(\mathrm{m}^{3} / \mathrm{s}\right) \\
C_{D, \text { in }} & =\text { Discharge Coefficient } \\
\text { A } & =\text { Opening area }\left(\mathrm{m}^{2}\right) \\
U_{R E F} & =\text { Reference velocity at building height }\left(\mathrm{m}^{2} / \mathrm{s}\right) \\
C p_{\text {in }} & =\text { Pressure coefficient at inlet opening } \\
C p_{\text {out }} & =\text { Pressure coefficient at outlet opening }
\end{array}
$$

The values are then substituded into Eq. (6) to calculate the internal pressure coefficient, $C p_{\text {internal }}$. Then, the cross ventilation rate for each case can be determined by using Eq. (7) with discharge coefficient

$C_{D, \text { in }}=0.67$, opening area $\mathrm{A}=8.28 \times 10^{-4} \mathrm{~m}^{2}$, reference velocity $U_{R E F}=6.97 \mathrm{~m} / \mathrm{s}$, and pressure coefficients for each cases respectively. The ventilation rate for all seven cases was shown in Figure 9. 
Table 3. Opening pressure coefficient and the difference between both pressure coefficient

\begin{tabular}{ccc}
\hline Opening Case & $\begin{array}{c}\text { Inlet Pressure } \\
\text { Coefficient, } C_{P, \text { in }}\end{array}$ & $\begin{array}{c}\text { Outlet Pressure } \\
\text { Coefficient, } C_{P, \text { out }}\end{array}$ \\
\hline Case 1 & 0.543617 & 0.020568 \\
Case 2 & 0.670806 & 0.182939 \\
Case 3 & 0.477500 & 0.016617 \\
Case 4 & 0.663078 & 0.144191 \\
Case 5 & 0.668487 & 0.158918 \\
Case 6 & 0.565787 & 0.067485 \\
Case 7 & 0.580102 & 0.094241 \\
\hline
\end{tabular}

Based on Figure 9, it is seen that the ventilation rate is the highest in Case 1 while lowest in Case 3 . The huge difference in ventilation rate between Case 1 and Case 3 is due to the difference in pressure difference between openings. For the cases of aligned openings, Case 1 with both openings at the top has $3.51 \%$ and $6.52 \%$ higher ventilation rate compared to Case 2 and 3 with openings at center and bottom respectively. For non-aligned opening cases, Case 4 and 5 have with inlet opening near the roof have $2.07 \%$ and $1.14 \%$ higher ventilation rate respectively compared to Case 6 with inlet opening placed at bottom and outlet placed near the roof. Case 7 with inlet opening at the bottom and outlet opening at the middle has $3.25 \%$ and $2.36 \%$ lower ventilation rate compared to Case 4 and 5 . Hence, the result proves that ventilation rate depends highly on pressure difference agrees well with Kleiven [15] which states that pressure difference is the main driving force for wind-induced cross ventilation. Furthermore, the results in terms of ventilation rate show good agreement with study done by Meroney [6] and Karava [9] which states that higher ventilation rate occurs when openings were placed near the roof.

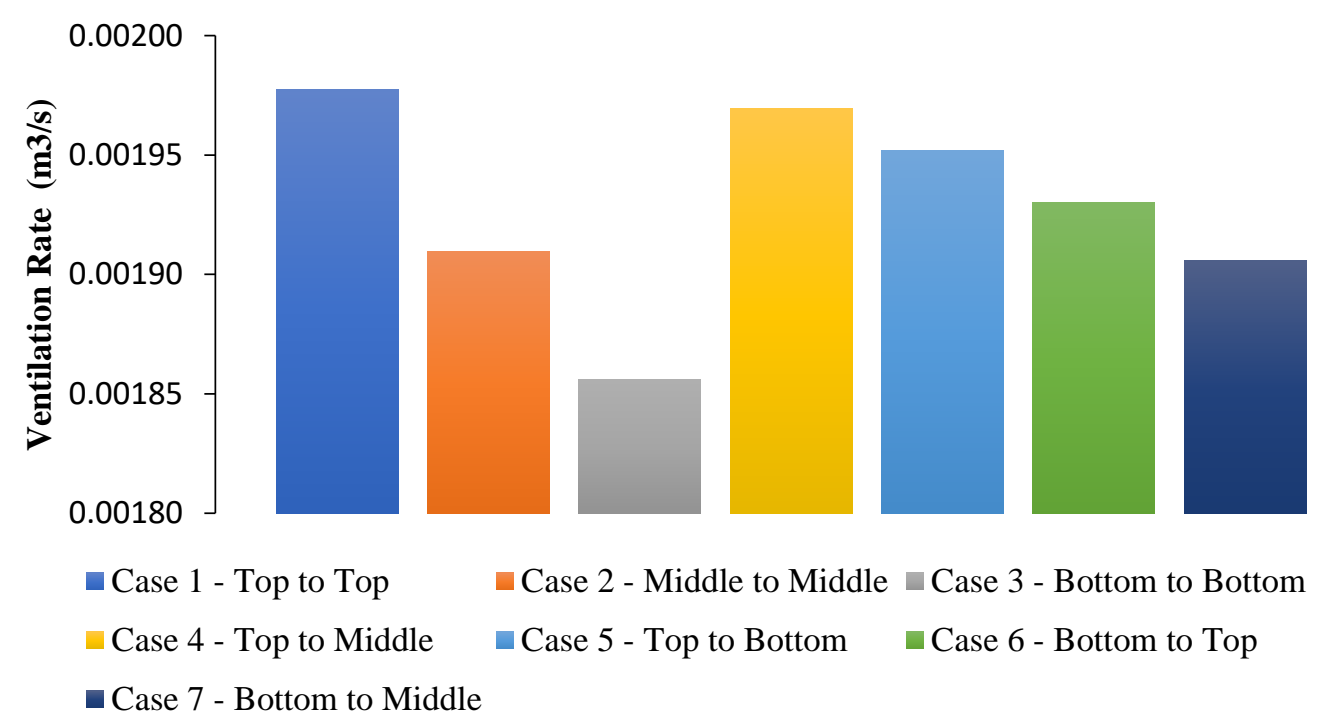

Figure 9. Ventilation rate for seven opening configurations

\section{CONCLUSION}

In this study, the effect of opening position on natural ventilation in an isolated building has been investigated. CFD simulation was done using seven different opening configurations on the building model whereby the inlet and outlet opening was varied on the windward and leeward wall. Computational domain was generated based on the study by Ramponi [10] and the simulation was done by interpreting an Atmospheric Boundary Layer (ABL) code which produces the velocity profile at the windward side of the model. Simulation was done using the 3D-RANS equation SST k- $\omega$. Results for reference case, Case 2 was used to perform grid sensitivity analysis as well as validation study with numerical simulation results by Ramponi. Both grid sensitivity analysis and validation study show great agreement between both simulation results. Result for all seven opening configurations was discussed in terms of velocity vector, contours, airflow mean streamwise speed, pressure coefficient, and ventilation rate. Based on the mean streamwise speed along the centerline between inlet and outlet opening, a common airflow trend was observed in all seven opening configurations in 
which the airflow with high velocity enters the building through inlet opening, the velocity decreases as it flow towards the middle of the building which then regains velocity as it approaches the outlet opening. In all seven cases, the pressure in front of the windward walls is high due to the impact of air onto the wall whilst the leeward side has relatively low pressure. Result shows both inlet and outlet openings placed near the roof generates highest ventilation rate with $6.52 \%$ higher compared to both openings placed near the ground. A higher ventilation rate is observed when inlet opening was placed near the roof rather than the outlet opening. Hence, it can be concluded that opening position significantly affects the natural cross ventilation across an isolated building. For future studies, it is recommended to include different wind incidence angle, different wind speed, and opening size to further investigate the parameters that affect the natural cross ventilation.

\section{ACKNOWLEDGEMENT}

The project is funded by the Ministry of Higher Education Malaysia, under the Fundamental Research Grant Scheme (FRGS Grant No: FRGS/1/2016/TK07/SEGI/02/1).

\section{REFERENCES}

[1] M. N. Khan, M. A. Khan, S. Khan, and M. M. Khan, "Effect of air conditioning on global warming and human health," Modern Age Environmental Problems and their Remediation, Eds. Cham: Springer International Publishing, pp. 83-94,2018.

[2] ASEAN, “The 4th ASEAN Energy Outlook 2013 - 2035,” ASEAN Cent. Energy Indones., pp. 98, 2015.

[3] L. K. Moey, K. S. Goh, D. L. Tong, P. L. Chong, N. M. Adam, and K. A. Ahmad, "A review on current energy usage and potential of sustainable energy in Southeast Asia countries,” J. Sustain. Sci. Manag., vol. 15, no. 2, pp. 89-107, 2020.

[4] P. C. Agrawal, "A review of passive systems for natural heating and cooling of buildings," Sol. Wind Technol., vol. 6, no. 5, pp. 557-567, 1989, doi: 10.1016/0741-983X(89)90091-X.

[5] WBCSD, "Energy Efficiency in Buildings," 2008.

[6] R. N. Meroney, "CFD prediction of airflow in buildings for natural ventilation", in Proceedings of the Eleventh Americas Conference on Wind Engineering, 2009.

[7] K. Kosutova, T. van Hooff, C. Vanderwel, B. Blocken, and J. Hensen, "Cross-ventilation in a generic isolated building equipped with louvers: Wind-tunnel experiments and CFD simulations,” Build. Environ., vol. 154, pp. 263-280, 2019, doi: 10.1016/j.buildenv.2019.03.019.

[8] Y. Tominaga and B. Blocken, "Wind tunnel analysis of flow and dispersion in cross-ventilated isolated buildings: Impact of opening positions," J. Wind Eng. Ind. Aerodyn., vol. 155, pp. 74-88, 2016, doi: 10.1016/j.jweia.2016.05.007.

[9] P. Karava, T. Stathopoulos, and A. K. Athienitis, "Airflow assessment in cross-ventilated buildings with operable façade elements,” Build. Environ., vol. 46, no. 1, pp. 266-279, 2011, doi: 10.1016/j.buildenv.2010.07.022.

[10] R. Ramponi and B. Blocken, "CFD simulation of cross-ventilation for a generic isolated building: Impact of computational parameters,” Build. Environ., vol. 53, pp. 34-48, 2012, doi: 10.1016/j.buildenv.2012.01.004.

[11] K. Zore, B. Sasanapuri, G. Parkhi, and A. Varghese, "ANSYS mosaic poly-hexcore mesh for high-lift aircraft configuration," presented at the 21st Annual CFD Symposium, Bangalore, 2019.

[12] K. Zore, D. Caridi, and I. Lockley, "Fast and accurate prediction of vehicle aerodynamics using ANSYS mosaic mesh," SAE Technical Paper, 2020.

[13] P. Karava, Airflow prediction in buildings for natural ventilation design : wind tunnel measurements and simulation, Concordia University, 2008.

[14] T. van Hooff, B. Blocken, and Y. Tominaga, "On the accuracy of CFD simulations of cross-ventilation flows for a generic isolated building: Comparison of RANS, LES and experiments," Build. Environ., vol. 114, pp. 148-165, 2017, doi: 10.1016/j.buildenv.2016.12.019.

[15] T. Kleiven, Natural Ventilation in Buildings: Architectural Concepts, Consequences, Possibilities. Norwegian University of Science and Technology, 2003. 